\title{
ANÁLISE DE IMPACTOS VIÁRIOS NO LICENCIAMENTO AMBIENTAL
}

\section{ANALYSIS OF TRAFFIC IMPACTS IN THE ENVIRONMENTAL LICENSING}

\section{Leonardo Barifouse ${ }^{1}$}

\section{Resumo}

A mobilidade urbana se apresenta, atualmente, como um dos principais desafios das cidades brasileiras - especialmente por conta da política industrial de incentivo às montadoras e da realização de grandes eventos internacionais. Neste contexto, revela-se essencial conferir, ao meio ambiente construído, a mesma relevância tradicionalmente reservada ao meio ambiente natural, de forma a permitir que o licenciamento ambiental contribua para a solução da questão, mediante o controle dos impactos viários negativos que os grandes empreendimentos urbanos são capazes de causar.

Palavras-chave: Mobilidade urbana - impactos viários - instrumentos de avaliação de impacto ambiental - estudo de impacto de vizinhança - licenciamento ambiental - discricionariedade e controle jurídico.

\section{Abstract}

The urban mobility presents itself nowadays as one of the Brazilian cities' main challenges especially because of the industrial policy of giving incentives to automobile manufacturers and the hosting of big international events. In this context, it's essential to provide the built environment with the same relevance regularly given to the natural environment, in order to allow the environmental licensing to contribute with the question's solution through the control of the negative traffic impacts that the big urban projects are able to cause.

Keywords: Urban mobility - traffic impacts - instruments of environmental impact evaluation neighborhood impact study - environmental licensing - discretion and juridical control.

\footnotetext{
${ }^{1}$ Mestre em Direito da Cidade pela UERJ. Especialista em Direito Ambiental pela PUC-RIO. Procurador do Estado do Rio de Janeiro. E-mail: barifouse@hotmail.com
} 


\section{A IMOBILIDADE NAS CIDADES}

Por várias décadas, o estímulo concedido pelo governo à indústria automobilística fez com que o transporte individual motorizado ocupasse cada vez mais, nos deslocamentos urbanos, a fatia antes reservada ao transporte público. ${ }^{2}$ Entretanto, nos últimos anos, a questão da mobilidade urbana tem ocupado lugar de destaque na pauta de reivindicações sociais. Disto são testemunhas os protestos de junho de 2013 - os quais, aliás, se iniciaram por conta do aumento das passagens de ônibus.

Não se discute a importância do setor automobilístico para a economia nacional, seja pela quantidade de empregos diretos que as montadoras fornecem, seja pelos importantes efeitos de encadeamento para frente e para trás, incluindo o efeito multiplicador em outros setores da economia. Neste passo, deve-se levar em conta que "todos os ciclos econômicos brasileiros desde 1967 se iniciaram nos setores de bens de consumo duráveis, em particular da cadeia automotiva", a qual "é a cadeia mais importante da economia brasileira quanto à indução direta e indireta de crescimento para todos os demais setores". 3

É digno de nota que, no contexto da crise econômica mundial iniciada em 2008, o pacote de medidas anticíclicas apresentado pelo governo federal contemplava a produção industrial de automóveis como uma das válvulas de escape para responder à esperada queda da demanda agregada. A desoneração do IPI operada em dezembro de 2008 fez com que as vendas de automóveis do primeiro semestre de 2009 superassem as do mesmo período de 2008, contribuindo com um aumento de $13,4 \%$ nas vendas, de acordo com estimativas do IPEA. ${ }^{4}$ Compensando-se a desoneração do IPI com o aumento de arrecadação decorrente das vendas estimuladas por esta política (não considerado o ICMS), o custo da redução da alíquota foi de

\footnotetext{
2 Por exemplo, na Grande São Paulo, a frota de veículos teve a seguinte evolução quantitativa: 96.000 em 1950; 120.660 em 1960; 492.000 em 1970; 1.719 .506 em 1976; e 2.676 .229 em 1985. Na Região Metropolitana de São Paulo, o número de carros passa de 573.010 (69,83 carros por mil habitantes) em 1970 para 2.123.854 (142,36 carros por mil habitantes) em 1980. Ainda na Região Metropolitana de São Paulo, a evolução do uso de transportes automotivos entre 1968 e 1975 foi: aumento de 28,6\% para 38,6\% com relação a carros particulares; avanço de $8,28 \%$ para $11,58 \%$ quanto aos táxis; e queda de $60,06 \%$ para $46,70 \%$ relativamente aos ônibus. Todos os dados foram extraídos de SANTOS, Milton. Metrópole corporativa fragmentada: o caso de São Paulo. 2a ed. São Paulo: Edusp, 2009.

${ }^{3}$ BAHIA, Luiz Dias; DOMINGUES, Edson Paulo. Estrutura de inovações na indústria automobilística brasileira. Texto para discussão no 1472. Brasília: IPEA, 2010. p. 11. O estudo aponta um efeito multiplicador de 2,47 e 2,23 para caminhões e automóveis, respectivamente, com preponderância do efeito indireto (57,3\% e 53\%), indicando uma repercussão importante nos demais setores da economia (p. 9).

${ }^{4}$ IPEA. Impactos da redução do imposto sobre produtos industrializados (IPI) de automóveis. Nota técnica no 15, 2009.
} 
aproximadamente $\mathrm{R} \$ 559$ milhões, para um aumento de 191.000 veículos (dos quais 100.000 a 120.000 eram nacionais) produzidos no período.

Segundo reportagem publicada no Estado de S. Paulo, três anos e meio após o início da crise, o país já tinha feito uma renúncia tributária de $\mathrm{R} \$ 26$ bilhões, muito embora o setor só tivesse criado 27.753 empregos, ou seja, cada novo posto de trabalho custou ao governo cerca de $\mathrm{R} \$ 1$ milhão. Por outro lado, as medidas permitiram uma remessa de US\$14,6 bilhões, a título de lucros e dividendos, das montadoras para suas matrizes deficitárias no exterior. ${ }^{5}$

A política econômica focada no consumo conjugada com a melhora da renda das camadas mais pobres gerou uma explosão de vendas de carros, ${ }^{6}$ sem a respectiva contrapartida de investimentos no transporte público e no sistema viário. Esgotado o ciclo de consumo, o balanço não foi tão positivo quanto o governo pretendia em princípio: cidades paralisadas por congestionamentos imensos e frequentes, afetando gravemente o bem-estar da população urbana e diminuindo a produtividade e competitividade da indústria e da mão-de-obra nacionais.

Estudo recente do Observatório das Metrópoles calculou um índice de bem-estar urbano (IBEU) para os 15 maiores aglomerados urbanos brasileiros, com base no censo do IBGE de 2010 e levando em consideração cinco dimensões: mobilidade urbana, condições ambientais urbanas, condições habitacionais urbanas, atendimento de serviços coletivos urbanos e infraestrutura urbana. ${ }^{7}$ A dimensão de mobilidade urbana utilizou como proxy o deslocamento casa-trabalho e adotou o padrão de 1 hora por dia no trajeto.

Os resultados do estudo foram bastante interessantes e ilustram bem o problema da mobilidade urbana. Como esperado, as regiões metropolitanas de São Paulo e Rio de Janeiro atingiram as piores colocações, porém a diferença é assombrosa: o IBEU-mobilidade da primeira é 12 vezes inferior à média das regiões, ao passo que o da segunda está 26 vezes abaixo. E não é só: as duas regiões metropolitanas são responsáveis por $54 \%$ dos municípios com IBEU-mobilidade inferior à metade do índice (abaixo de 0,500), sendo que, no caso do Rio de Janeiro, 60\% dos

\footnotetext{
5 "Indústria automobilística teve isenção de R\$ 1 milhão por emprego criado. " Estado de S. Paulo, Caderno de Economia, B4, 02/07/2012.

6 "Segundo dados do DENATRAN, entre janeiro de 2010 e dezembro de 2015, a frota total do Município de São Paulo aumentou de 6.160.138 veículos automotivos para 7.590.181 (aumento de 23,2\%) e do Município do Rio de Janeiro, de 1.956 .818 para 2.667 .780 (36,3\% a mais). Para se ter uma ideia mais completa do fenômeno, cabe analisar, por exemplo, o aumento da frota total das cinco maiores cidades da Região Metropolitana do Rio de Janeiro no mesmo período: São Gonçalo, de 163.129 para 274.224 (68,1\%); Duque de Caxias, de 150.889 para 248.697 (64,8\%); Nova Iguaçu, de 136.446 para 223.551 (63,8\%); Niterói, de 198.660 para 257.954 (29,8\%); São João de Meriti, de 80.539 para 130.175 (61,6\%).

7 RIBEIRO, Luiz Cesar de Queiroz; RIBEIRO, Marcelo Gomes (org.). IBEU: índice de bem-estar urbano. Rio de Janeiro: Letra Capital, 2013.
}

Revista de Direito da Cidade, vol. 08, no 3. ISSN 2317-7721 pp.934-951 936 
municípios apresentaram tal resultado. Entretanto, a ausência de mobilidade urbana não é um fenômeno localizado no eixo Rio-São Paulo, como pode parecer à primeira vista, pois, mesmo em alguns aglomerados onde o IBEU-mobilidade é superior ao IBEU-geral, os pesquisadores identificaram tal resultado com a degradação das demais dimensões do índice, em vez de uma elevada qualidade da mobilidade urbana.

A discussão ganhou ainda mais relevo com os megaeventos esportivos programados nos últimos anos (Copa do Mundo de 2014 e Olimpíadas de 2016) - tanto por conta dos projetos de mobilidade urbana como pelos estrangulamentos viários causados pelas obras correlatas. Canteiros de obras por toda parte, interdições e demolições de vias, descontrole do tráfego, linhas de ônibus superpostas, atrasos nos cronogramas dos projetos, investimentos não concretizados e promessas não cumpridas de novos modais ou expansões - este se tornou o triste cotidiano do habitante dos grandes centros urbanos brasileiros.

Não se pode esquecer que, em 2012, foi editada a Lei № 12.587, instituindo o Plano Nacional de Mobilidade Urbana. Embora suas disposições se mostrem bastante tímidas diante do real desafio, os princípios veiculados neste diploma podem servir de diretriz hermenêutica no tratamento de questões relacionadas à mobilidade urbana.

\section{IMPACTO AMBIENTAL VIÁRIO}

Não é difícil perceber que o momento demanda uma reflexão mais profunda sobre a mobilidade urbana. Como ensina JOSÉ AfONSO DA SILVA, "uma das funções da atividade urbanística do Poder Público consiste em dar condições à circulação. Não se compreenderia aglomerado urbano sem meios regulares de circulação." ${ }^{8}$ A livre circulação pela cidade é uma relação essencial do cidadão com o meio urbano que o cerca - é o que torna viva a urbe e é o que permite ao indivíduo participar do espírito próprio de cada aglomeração urbana. A mobilidade urbana, portanto, constitui um aspecto fundamental da preservação da qualidade do ambiente urbano.

Toda obra ou empreendimento que intervenha de forma mais relevante no tecido urbano gera um impacto ambiental. Tal impacto deve ser - mas muitas vezes não é - levado em conta no processo de licenciamento ambiental. Há, ainda, certo viés no diagnóstico ambiental no sentido de que devem ser priorizadas e aprofundadas as questões do ambiente natural, sendo as demais questões tratadas de forma perfunctória.

\footnotetext{
${ }^{8}$ SILVA, José Afonso da. Direito Urbanístico brasileiro. 7ạ ed. São Paulo: Malheiros, 2012. p. 179.
} 
Ora, tal visão não pode prevalecer diante de uma perspectiva holística de meio ambiente. O conceito contemporâneo de meio ambiente inclui, além do patrimônio natural, o ambiente cultural e o ambiente artificial, ${ }^{9}$ e leva inevitavelmente à projeção de cidades sustentáveis.

Não significa isto que o Direito Urbanístico perca sua autonomia e se reduza à aplicação do Direito Ambiental ao meio ambiente construído. Deve-se manter a "percepção de que os princípios de direito ambiental e de direito urbanístico findam por fundir-se para a otimização do direito da cidade", porém "não se pode deixar também de lembrar de alguns princípios específicos do citado e autônomo ramo denominado direito urbanístico". ${ }^{10}$

É reconhecer que uma parte da ordenação urbana pode ser reconduzida ao conceito de proteção ambiental, utilizando, portanto, os instrumentos desenvolvidos pelo Direito Ambiental. Trata-se de uma coexistência dialógica, em que um é capaz de auxiliar o outro, sem canibalizá-lo. ${ }^{11}$ Por exemplo, normas edilícias consistem em instrumento típico do Direito Urbanístico, sem maior relevância para o Direito Ambiental, ao passo que o licenciamento ambiental, objeto do presente trabalho, pode e deve abordar impactos causados ao ambiente urbano.

É neste sentido que o licenciamento ambiental é um instrumento fundamental de concretização do princípio constitucional da função social das cidades (art. 182, caput, CF). A gestão democrática das cidades, consagrada no art. 2ำ, II, do Estatuto da Cidade, impõe que a sociedade seja informada das possíveis degradações do ambiente urbano e possa deliberar sobre sua mitigação ou prevenção, propondo e adotando alternativas às intervenções urbanas.

\footnotetext{
${ }^{9}$ MILARÉ, Édis. Direito do ambiente. 8a ed. São Paulo: Revista dos Tribunais, 2013. p. 503.

${ }^{10}$ BONIZZATO, Luigi. Função ambiental da cidade, Plano Diretor e validade das normas urbanísticas. In: MOTA, Mauricio (coord.). Função social do Direito Ambiental. Rio de Janeiro: Elsevier, 2009. p. 180. Esclarecendo o conceito científico de Direito Urbanístico, SILVA, José Afonso da. Direito Urbanístico brasileiro. p. 38: "São, pois, normas do direito urbanístico todas as que tenham por objeto disciplinar o planejamento urbano, as áreas de interesse especial (como a execução das urbanificações, o disciplinamento dos bens urbanísticos naturais e culturais), a ordenação urbanística da atividade edilícia e a utilização dos instrumentos de intervenção urbanística."

11 "Assim, o direito urbanístico visa precipuamente à ordenação das cidades, mas seus preceitos incidem também sobre as áreas rurais, no vasto campo da ecologia e da proteção ambiental, intimamente relacionadas com as condições da vida humana em todos os núcleos populacionais, da cidade ou do campo. Pois é fato inconteste que a qualidade de vida dos moradores urbanos depende fundamentalmente dos recursos da Natureza, e muito em particular das terras, das águas e das florestas que circundam as grandes e as pequenas cidades, assim como das atividades exercidas em seus arredores." MEIRELLES, Hely Lopes. Direito municipal brasileiro. 14a ed. São Paulo: Malheiros, 2006. p. 514-515.
} 


\section{ESTUDANDO O IMPACTO VIÁRIO}

A Lei no 6.938/81 previu, como um dos instrumentos da Política Nacional do Meio Ambiente, o prévio licenciamento ambiental (com a respectiva revisão) para construção, instalação, ampliação e funcionamento de estabelecimentos e atividades utilizadores de recursos ambientais, efetiva ou potencialmente poluidores ou capazes, sob qualquer forma, de causar degradação ambiental (art. 9o, IV, c/c art. 10).

O licenciamento ambiental deve contemplar, incontornavelmente, uma avaliação de impacto ambiental (AIA), isto é, "uma avaliação técnica e prévia (vale dizer, a priori e não a posteriori) dos riscos e danos potenciais que determinado empreendimento ou ação pode causar às características essenciais do meio, seus recursos e seu equilíbrio ecológico". ${ }^{12}$

Sem dúvida, a modalidade mais conhecida de AIA é o estudo prévio de impacto ambiental, acompanhado do respectivo relatório de impacto ambiental (EIA/RIMA), destinado aos empreendimentos potencialmente causadores de significativa degradação do meio ambiente (art. 225, IV, CF). O EIA/RIMA é requerido para casos de significativa degradação ambiental e, portanto, é um estudo mais complexo. Nos demais casos de degradação ou utilização de recursos ambientais, como já reconhecido pela Resolução no 237/97 do CONAMA, o órgão ambiental competente definirá os outros estudos ambientais pertinentes ao licenciamento, ${ }^{13}$ tais como relatório ambiental, plano e projeto de controle ambiental, relatório ambiental preliminar, diagnóstico ambiental, plano de manejo, plano de recuperação de área degradada e análise preliminar de risco. ${ }^{14}$

A consideração de aspectos urbanísticos na AIA do licenciamento ambiental pode gerar dúvidas quanto à sobreposição, duplicidade e até contradição com eventual estudo de impacto de vizinhança (EIV) - espécie de AIA ${ }^{15}$ prevista na Lei no 10.257/01 (Estatuto da Cidade) como instrumento urbanístico, e não como estudo a ser efetuado no processo de licenciamento. $\mathrm{O}$ art. 37 do Estatuto da Cidade determina que o EIV seja "executado de forma a contemplar os efeitos positivos e negativos do empreendimento ou atividade quanto à qualidade de vida da população residente na área e suas proximidades". Dentre os impactos do empreendimento, constitui um dos

\footnotetext{
12 MILARÉ, Édis. Direito do ambiente. p. 740.

${ }^{13}$ Art. 3으, parágrafo único.

${ }^{14}$ Art. 1으, III.

${ }^{15}$ Sobre a opinião de que o EIV é uma modalidade de AIA, cf. MILARÉ, Édis. Direito do ambiente. p. 740.
} 
requisitos mínimos da análise a ser efetuada no EIV justamente a geração de tráfego e a demanda por transporte público (inciso V).

Surge, então, a discussão sobre a conveniência de se avaliar o impacto viário no licenciamento ambiental, diante da previsão expressa de outro instrumento na legislação urbanística, ainda mais considerando-se a solução normativa do art. 38 do Estatuto, que impede que o EIV substitua o EIA, quando o mesmo for requerido pela legislação ambiental - mas nada fala acerca das outras avaliações de impacto ambiental.

De uma forma geral, tal superposição dos estudos tem sido debatida na doutrina, em especial com relação ao EIA/RIMA. Não é incomum encontrar ainda uma visão restritiva do conceito de meio ambiente, como anteriormente explicitado, desconsiderando os impactos no ambiente construído como verdadeiros impactos ambientais. Nesta linha, à primeira vista, o EIV não analisaria impactos ambientais, que seriam analisados no EIA. ${ }^{16}$ Segundo tal entendimento, o impacto viário, obrigatoriamente avaliado no EIV, poderia, por este motivo, ser prescindido no EIA.

Uma posição mais radical - e que pode esbarrar na redação do art. 38 do Estatuto da Cidade - é a suficiência do EIV para a análise dos impactos ambientais das atividades a ele submetidas. PAULO DE BESSA ANTUNES defende a suficiência do EIV para análise de impactos no ambiente urbano causados por atividades não-industriais:

Todos aqueles que militam na área da proteção ao meio ambiente sabem que os estudos de impacto ambiental têm uma vocação eminentemente industrial, ou, no mínimo, de projetos que signifiquem intervenção em ambiente não urbanizado. No entanto, à míngua de outras normas, o EIA passou a ser exigido pelos órgãos ambientais para a implantação de shopping centers, condomínios e outros empreendimentos semelhantes. Tais Estudos de Impacto, de acordo com os seus termos de referência, normalmente, têm por objetivo investigar os assuntos relacionados como conteúdo mínimo do EIV. Penso que o EIV é um instrumento mais do que suficiente para que se avaliem os impactos gerados por uma nova atividade a ser implantada em área urbana - não se tratando de atividade industrial. Penso que o EIV nada mais é do que um EIA para áreas urbanas e, data venia, creio ser completamente destituída de lógica ou razão a obrigatoriedade de ambos os estudos. ${ }^{17}$

Contudo, não resta claro, na posição do autor, quais características das atividades industriais a diferenciariam das demais quanto à insuficiência do EIV e se, para as atividades

${ }^{16}$ SOARES, Lucéia Martins. Estudo de impacto de vizinhança (arts. 36 a 38). In: DALLARI, Adilson Abreu; FERRAZ, Sérgio (org.). Estatuto da Cidade. 2a ed. São Paulo: Malheiros, 2006. p. 308.

${ }^{17}$ ANTUNES, Paulo de Bessa. Direito Ambiental. 11a ed. Rio de Janeiro: Lumen Juris, 2008. p. 315-316. 
industriais, bastaria o EIA/RIMA ou seria necessária a simultaneidade de EIV e EIA/RIMA. Mostra-se também bastante peculiar a definição do EIV como uma espécie de EIA/RIMA para áreas urbanas, diante da diferença na profundidade de metodologia e na complexidade do respectivo procedimento.

Há quem entenda, ao revés, que o EIV não seria, a rigor, necessário, pois o EIA deve incluir também o meio ambiente urbano, e sua criação se deve apenas ao costume de se restringir o conceito de meio ambiente ao ambiente natural. Em realidade, o EIV se distinguiria apenas em forma e metodologia quanto aos impactos ambientais urbanos. ${ }^{18}$

De qualquer forma, o que se observa em todas as posições acerca da controvérsia é a preocupação com a redundância dos estudos. Tal repetição desnecessária, muitas vezes, é uma decorrência da estrutura federativa peculiar do Estado brasileiro e da tradição burocrática da nossa Administração. ${ }^{19}$

Quanto à questão, deve-se notar, em primeiro lugar, que o art. 36 do Estatuto da Cidade concede à lei municipal um espaço de definição das atividades urbanas sujeitas ao EIV, ou seja, a análise do impacto viário estaria sujeita à liberdade de conformação da legislatura de cada Município. Significa dizer que, a depender da omissão ou da legislação defeituosa dos Municípios, os impactos ao ambiente construído podem ocorrer sem o devido controle, caso se conclua pela sua não inclusão no licenciamento ambiental.

Por outro lado, é comum olvidar-se que a modalidade de avaliação de impacto ambiental varia segundo o tipo de empreendimento licenciado e a gravidade do risco ou da degradação ambiental. Assim, O EIA/RIMA não é a única alternativa ao EIV para análise dos impactos ambientais urbanos. De fato, se a atividade não puder potencialmente causar significativa degradação, o EIA/RIMA não será requerido.

Com efeito, o fato de o empreendimento estar sujeito ao licenciamento não quer dizer que o EIV não seja suficiente à análise do impacto viário - por vezes, é o que se mostra necessário para uma correta avaliação sem a produção de maiores custos ao empreendedor. Não obstante, caso o EIV não tenha a abrangência necessária para avaliar integralmente o impacto viário, poderá ser

18 DALLARI, Adilson Abreu. Instrumentos da política urbana (art. 4ํ). In: DALLARI, Adilson Abreu; FERRAZ, Sérgio (org.). Estatuto da Cidade. 2a ed. São Paulo: Malheiros, 2006. p. 84-85.

${ }^{19}$ A referida redundância burocrático-administrativa é muito comum no Direito Ambiental e levou, por exemplo, à edição da Lei Complementar no 140/11, para evitar o múltiplo licenciamento, bem como à exigência de inúmeros cadastros e registros públicos, conforme já tratado no estudo anterior BARIFOUSE, Leonardo. Integração e fragmentação no Cadastro Ambiental Rural (CAR). Revista de Direito Ambiental. v. 75, jul./set. 2014. p. 93-111.

Revista de Direito da Cidade, vol. 08, no 3. ISSN 2317-7721 pp.934-951 
complementado, durante o licenciamento, por outra modalidade de AIA. É claro que, quanto maior a potencial degradação projetada, mais profundo será o estudo ambiental requerido (até se alcançar a necessidade do EIA/RIMA), configurando, de forma mais evidente, a limitação do EIV e a necessidade de sua complementação. ${ }^{20}$

O importante é ter em mente que o impacto viário, enquanto impacto ambiental ao meio ambiente construído, afeta o bem-estar dos indivíduos na relação com seu entorno e, por conseguinte, não pode ser ignorado ou subavaliado na consideração da degradação causada pelo empreendimento - até mesmo para que se adotem as respectivas medidas preventivas ou mitigadoras.

É claro que, dentro do contexto do desenvolvimento sustentável, a proteção ambiental deve prezar pela eficiência e considerar os custos impostos ao empreendedor na produção dos estudos ambientais requeridos. Contudo, o EIV possui um evidente escopo urbanístico, sendo certo que, algumas vezes, sua abrangência mais limitada obstará a plena avaliação da potencial degradação ambiental. Em outras palavras, a conformação da atividade à disciplina urbanística não importa ipso facto na sua viabilidade ambiental com relação ao meio ambiente urbano:

Não só todos os serviços públicos prestados na região (transporte, infra-estrutura, saneamento etc.), como também os simples comportamentos daqueles que habitam nas proximidades podem ser afetados pela tão-só construção de um empreendimento - repita-se -, ainda que em conformidade com toda a legislação urbanística que disciplina a forma pela qual ele deve ser levado a efeito. ${ }^{21}$

Portanto, para impactos mais relevantes no tráfego urbano (principalmente, em áreas mais extensas da cidade), uma análise de impacto ambiental realizada no licenciamento ambiental se mostra mais adequada do que somente o estudo de impacto de vizinhança - até para que a população e o administrador possam levar em conta o impacto viário como um dos fatores de ponderação na concessão da licença ambiental.

\footnotetext{
20 Também ressaltando as limitações do EIV - ainda que diante apenas do EIA - e a possibilidade de dupla sujeição, MIRRA, Álvaro Luiz Valery. Estudos de impacto de vizinhança no Direito brasileiro. In MARQUES, Claudia Lima; MEDAUAR, Odete; SILVA, Solange Teles da (coord.). O novo Direito Administrativo, Ambiental e Urbanístico: estudos em homenagem a Jacqueline Morand-Deviller. São Paulo: Revista dos Tribunais, 2010. p. 263.

${ }^{21}$ SOARES, Lucéia Martins. Estudo de impacto de vizinhança (arts. 36 a 38). p. 307.
} 


\section{A ANÁLISE DE IMPACTO VIÁRIO NOS ESTUDOS AMBIENTAIS}

Estabelecida a premissa de que o impacto viário de um grande empreendimento constitui um impacto ambiental ao ambiente construído, cabe verificar de que forma sua análise deve ser procedida no curso do licenciamento ambiental.

Em primeiro lugar, cumpre destacar que, em caso de intervenções urbanas mais profundas (até o nível das reformas urbanas), a análise do impacto viário tem que levar em conta o efeito cumulativo e sinérgico dos empreendimentos que simultaneamente estejam sendo realizados na cidade. A depender da dinâmica própria de cada cidade e do respectivo momento de desenvolvimento urbanístico, é essencial calibrar adequadamente o estudo de sinergia com outros empreendimentos de considerável importância e/ou dimensão.

Na hipótese de EIA/RIMA, até por conta da necessidade de estudo mais aprofundado da significativa degradação ambiental, é indiscutível que a execução paralela de várias obras de grande magnitude demanda tal avaliação cruzada.

A título ilustrativo, veja-se a situação da cidade do Rio de Janeiro, que, nos últimos anos, tem sofrido inúmeras intervenções simultâneas, com fortíssimo impacto no trânsito: no Centro, a demolição da Perimetral, com a interdição de inúmeras vias da zona portuária, e a construção do veículo leve sobre trilhos no principal eixo viário da área (Avenida Rio Branco); na Zona Norte, a reforma do estádio do Maracanã, com a construção de novos acessos, e a construção de piscinas subterrâneas para evitar alagamentos; na Zona Sul, a expansão da linha 1 conjuntamente à construção da linha 4 do metrô e a duplicação do Elevado do Joá; na Zona Oeste, a construção de várias linhas de BRT, de novos eixos viários expressos (Transcarioca, Transolímpica etc.) e do trecho final da linha 4 do metrô. Desconsiderar a cumulatividade do tráfego causado por cada uma destas obras é ter um diagnóstico totalmente afastado da dura realidade que o cidadão carioca é chamado a enfrentar cotidianamente.

Neste exemplo, fica claro que todas estas obras tinham uma unidade finalística decorrente da realização de megaeventos esportivos na cidade. Ao se destacar do planejamento coletivo cada uma das obras, não ocorreu propriamente o problema do licenciamento por partes, ${ }^{22}$ porém cresceu enormemente a necessidade de uma análise criteriosa da sinergia dos impactos.

\footnotetext{
22 Adverte o mestre PAULO AfFonso LEME MACHADO: "Licenciar por partes pode representar uma metodologia ineficiente, imprecisa, desfiguradora da realidade, e até imoral: analisando-se o projeto em fatias isoladas, e não sua totalidade ambiental, social e econômica, podendo ficar ocultas as falhas e os danos potenciais, não
} 
O estudo da influência mútua das grandes obras e empreendimentos é um pressuposto da implantação de um urbanismo planejado. E "não há como garantir o direito ao meio ambiente, bem como o direito ao desenvolvimento nacional equilibrado sem planejamento" ${ }^{23}$

Embora as cidades possuam uma força espontânea no seu crescimento e na sua reinvenção, que proporciona a cada uma delas uma marca distintiva própria, o crescimento desordenado não é admitido, sendo papel do Estado estabelecer balizamentos que impeçam o fenômeno urbano de cair no abismo do caos. ${ }^{24}$

No crescimento urbano planejado, as políticas públicas urbanas se direcionam conjuntamente a fins previamente estabelecidos e se refletem na regulação das atividades privadas. O planejamento é indicativo para o setor privado (art. 174, caput, CF), mas, nos aspectos em que as atividades econômicas estão sujeitas ao controle estatal - em especial, nas questões ambientais (art. 170, VI, CF) -, a adesão dos particulares é uma decorrência direta da Constituição Federal. ${ }^{25}$

O direito à cidade sustentável é o direito à cidade planejada. Nesta linha, o planejamento urbano deve se refletir no licenciamento ambiental das atividades e empreendimentos que causem um impacto mais profundo no ambiente construído, de forma a permitir um maior controle social. ${ }^{26}$

Neste sentido, é indispensável a demonstração, pelo empreendedor, da adequação da atividade não só ao Plano Diretor, mas também a qualquer plano viário ou de mobilidade urbana que esteja sendo desenvolvido e/ou implantado na cidade. Ressalte-se que um dos princípios estabelecidos pela Lei no 12.587/12 para a Política Nacional de Mobilidade Urbana é a "eficiência,

se podendo saber se as soluções parciais propostas serão realmente aceitáveis." MACHADO, Paulo Affonso Leme. Direito Ambiental brasileiro. 21a ed. São Paulo: Malheiros, 2013. p. 342.

23 PIOVESAN, Flávia. O direito ao meio ambiente e a Constituição de 1988. In: BENJAMIN, Antonio Herman; FIGUEIREDO, Guilherme José Purvin (coord.). Direito Ambiental e as funções essenciais à justiça. São Paulo: Revista dos Tribunais, 2014. p. 69.

24 BARIFOUSE, Leonardo. O planejamento urbano entre a ordem e o caos. Revista de Direito da Cidade. v. 5, n. 1, 2013, p. 146-169.

${ }^{25}$ A busca da cidade sustentável prevista no art. 182 da Constituição demanda, como determinado pelo Estatuto da Cidade, um "planejamento do desenvolvimento das cidades, da distribuição espacial da população e das atividades econômicas do Município e do território sob sua área de influência, de modo a evitar e corrigir as distorções do crescimento urbano e seus efeitos negativos sobre o meio ambiente" (art. 2으, IV).

26 "À medida que se concebe o planejamento como direito difuso, torna-se imprescindível a participação, o controle e a fiscalização da sociedade civil quando da consecução do planejamento urbanístico, bem como quando de sua aplicação." PIOVESAN, Flávia. O direito ao meio ambiente e a Constituição de 1988. p. 81. 
eficácia e efetividade na circulação urbana" (art. 5o, IX), o que obviamente deve ser considerado nos impactos ambientais ao ambiente construído.

É importante frisar que o impacto viário pode dizer respeito ao deslocamento de maquinário e mão-de-obra para o local de implantação do empreendimento (isto é, sua construção) ou pode decorrer diretamente do exercício da atividade (por exemplo, inauguração de nova via expressa) - nalgumas vezes, nos dois sentidos. A análise do impacto viário precisa abordar as duas facetas, seja quanto aos impactos negativos, seja quanto aos impactos positivos (por exemplo, no caso de implantação de novo modal de transporte público).

Por fim, insta salientar que é imposto ao empreendedor, especialmente no EIA/RIMA, a apresentação de medidas mitigadoras do impacto viário de sua atividade (art. 6으, III c/c art. 9ㅇ, VI, Resolução CONAMA no 001/86). Exemplos de medidas mitigadoras seriam a contratação, treinamento e designação de agentes de tráfego para pontos nodais, a construção de vias provisórias de escape ou, ainda, a colocação à disposição da população de meios de transporte paliativos. Ora,

a Administração Pública, embora não proíba a construção da obra ou exploração da atividade, tenta intervir de maneira a evitar que haja perturbação no cotidiano daqueles que habitam na região ou, pelo menos, tenta amenizar ao máximo a intensidade daquela. ${ }^{27}$

Assim, uma vez constatado o alto impacto viário negativo, é indispensável a apresentação de um plano articulado de medidas mitigadoras. Não só: este plano deve contemplar as propostas de acompanhamento de sua implementação, bem como alternativas de ajuste (art. 9o., VII, Resolução CONAMA no 001/86).

De fato, tais medidas têm que contar com acompanhamento e feedback, para que sejam devidamente ajustadas, na medida em que o tráfego de veículos é essencialmente dinâmico e pode provocar a saturação não esperada de vias alternativas. Mesmo nas vias diretamente afetadas, a intensidade do impacto viário pode ser maior do que aquela previamente diagnosticada.

É fácil observar que a análise do impacto viário se mostra mais complexa do que pode parecer numa leitura mais apressada. Portanto, o licenciamento ambiental não conseguirá alcançar o fim a que se propõe se não contar com a devida assessoria jurídica e, principalmente, com um sério controle jurídico.

${ }^{27}$ SOARES, Lucéia Martins. Estudo de impacto de vizinhança (arts. 36 a 38). p. 307. 


\section{CONTROLE JURÍDICO NO LICENCIAMENTO AMBIENTAL}

Como todo processo administrativo, o licenciamento ambiental deve passar sob o crivo constante do controle de juridicidade. Entretanto, a juridicidade não se limita, como em outras hipóteses, à legalidade procedimental. No processo de licenciamento, há ampliação do controle jurídico para abarcar, durante todas as fases, a defesa do meio ambiente como dever fundamental, previsto no art. 225 da Constituição, com a consequente limitação da margem de discricionariedade da Administração Ambiental:

Em outras palavras, pode-se dizer que os deveres de proteção ambiental conferidos ao Estado vinculam os poderes estatais de tal modo a limitar a sua liberdade de conformação na adoção de medidas atinentes à tutela do ambiente. No caso especialmente do Poder Executivo, há uma clara limitação ao seu poder-dever de discricionariedade, de modo a restringir a sua margem de liberdade na escolha das medidas protetivas do ambiente, sempre no intuito de garantir a maior eficácia possível do direito fundamental ao ambiente. ${ }^{28}$

Para o efetivo controle da sociedade sobre os impactos ambientais que a cidade sofre, é indispensável que as instâncias de controle interno do processo de licenciamento sejam atuantes na garantia da disponibilidade e publicidade das informações do diagnóstico e prognóstico ambientais. Neste desiderato, o advogado público se mostra um agente de especial relevância, no regular exercício da defesa do interesse público primário. Devido à ampla competência concedida aos Estados (e ao Distrito Federal) pela Lei Complementar no 114/10, o controle realizado, em especial, pelo Procurador de Estado se mostra de fundamental importância para a proteção da sociedade no licenciamento ambiental de grandes projetos.

Como é amplamente sabido, os órgãos ambientais e seus técnicos, infelizmente, não contam com a estrutura nem com a autonomia funcional imprescindíveis a uma avaliação crítica e isenta da potencial degradação ambiental. ${ }^{29}$ Neste sentido, o controle jurídico interno auxilia

\footnotetext{
${ }^{28}$ FENSTERSEIFER, Tiago. Direitos fundamentais e proteção do ambiente: a dimensão ecológica da dignidade humana no marco jurídico-constitucional do Estado Socioambiental de Direito. Porto Alegre: Livraria do Advogado, 2008. p. 223-224.

29 “Na área da proteção ambiental, certamente é justificada a desconfiança em relação aos atos emanados dos órgãos administrativos formalmente competentes, que tradicionalmente tiveram grandes dificuldades no controle das atividades degradadoras. Os órgãos ambientais brasileiros costumam apresentar uma série de limitações relacionadas ao preparo técnico de seu pessoal, organização institucional e estrutura física, autonomia na tomada de decisões polêmicas e a sua própria legitimidade de negociação. " KRELL, Andreas Joachim. A convivência funcional dos órgãos administrativos e judiciais no controle da discricionariedade no âmbito da proteção ao meio ambiente: aspectos político-ideológicos da ação civil pública. In: TRENNEPOHL, Curt; TRENNEPOHL, Terence (coord.). Direito Ambiental atual. 1a ed. Rio de Janeiro: Elsevier, 2014. p. 26.
}

Revista de Direito da Cidade, vol. 08, no 3. ISSN 2317-7721 pp.934-951 946 
levantando questões a serem abordadas em eventual pedido de complementação de informações ao empreendedor (art. 10, IV, Resolução CONAMA no 237/97 e art. 14, LC no 114/10). Pode verificar, também, se os esclarecimentos requeridos pela população na audiência pública estão sendo corretamente atendidos pelo empreendedor (art. 10, VI, Resolução CONAMA no 237/97).

Entretanto, por mais que o advogado público, no exercício da atividade consultiva junto aos órgãos ambientais, goze de uma posição privilegiada em relação aos integrantes daquela estrutura administrativa, muito pouco se acrescerá caso os órgãos de advocacia pública não sejam instituições fortes e deem o devido respaldo ao trabalho de seus integrantes:

É em razão do diuturno e incessante trabalho dos advogados públicos na área da consultoria jurídica que o Estado, bem ou mal, mesmo em face da maior agressividade de setores da economia pouco afetos à proteção do meio ambiente, ainda zela pelo cumprimento da legislação vigente, impondo a realização de estudos prévios de impacto ambiental, apresentando condicionantes para a concessão de licenças ambientais, procedendo ao embargo ou interdição de atividade industrial poluente ou à guarda de unidades de conservação da natureza, realizando a apreensão de equipamentos para caça ou pesca em área protegida, demolindo construções irregulares antes mesmo que a notícia da irregularidade chegue aos meios de imprensa ou ao Ministério Público. Se o quadro está muito longe de configurar-se exemplar, isso se deve em muito à fragilidade política e institucional das instituições de Advocacia de Estado [...]. ${ }^{30}$

Por óbvio, não é dado ao advogado público substituir o administrador na sua margem de discricionariedade, tampouco a sociedade na discussão e decisão acerca da viabilidade ambiental do empreendimento. Todavia, o advogado público pode e deve assegurar que a avaliação do impacto ambiental contemple de forma integral os impactos positivos e negativos e descreva criteriosamente a potencial degradação ambiental, garantindo às instâncias decisórias institucionalizadas subsídios suficientes à deliberação sobre a concessão da licença e a imposição das medidas preventivas e mitigadoras.

A autonomia técnico-funcional do advogado público é especialmente importante nos tormentosos casos de autolicenciamento, isto é, licenciamento ambiental de empreendimentos do próprio ente federativo licenciador. Mesmo no caso de entes federativos distintos, dependendo da magnitude dos projetos e das alianças políticas envolvidas, o licenciamento se mostra às vezes contaminado por fortes considerações de outro matiz. Como destaca GUILHERME PURVIN:

\footnotetext{
${ }^{30}$ FIGUEIREDO, Guilherme José Purvin. Advocacia Pública e a defesa do meio ambiente à luz do art. 225 da CF. In: BENJAMIN, Antonio Herman; FIGUEIREDO, Guilherme José Purvin (coord.). Direito Ambiental e as funções essenciais à justiça. São Paulo: Revista dos Tribunais, 2014. p. 45.
} 
Se não pode um Procurador do Estado prosseguir na execução fiscal de uma multa ambiental cujo valor apontado é sabidamente errado - digamos, um erro material que eleve em mil vezes o valor da multa -, pena de estar infringindo o princípio da impessoalidade e onerando injustamente o réu, por motivos muito mais ponderáveis não poderá obstinar-se na postergação da mitigação de dano ambiental incontestavelmente causado pelo Estado empreendedor, pena de estar onerando de forma extremamente grave a vida e a saúde das presentes e futuras gerações. Nesse sentido, resgatando sua perspectiva jurídico-constitucional, a Advocacia de Estado deve estar muito mais próxima de uma ponderada atuação do Ministério Público do que daquela do governante que despreza os compromissos constitucionais de manutenção da ordem jurídica ambiental. ${ }^{31}$

De qualquer forma, ao garantir um licenciamento procedido com o rigor legal e com estudos técnicos robustos, o controle realizado pela advocacia pública acaba por configurar uma atividade preventiva de conflitos, o que fortalece ainda mais seu papel institucional na defesa do interesse público e do ente federativo.

O controle pelos órgãos de advocacia pública pode suprir as deficiências do órgão ambiental (como estudos de baixa qualidade e audiências públicas malconduzidas) que prejudicam a publicidade e a participação popular, bem como assegura que conflitos ambientais sejam discutidos e maturados nas instâncias de procedimento administrativo, antes de alcançarem o Judiciário. $^{32}$

Com efeito, a licença ambiental não está infensa à revisão judicial, mas obriga o julgador a levar em conta os juízos efetuados pela Administração. Mesmo que a adoção da teoria do risco integral permita superar a licitude do ato impugnado, o poder estatal, ao apreciar a mesma situação fática, não pode aplicar o instrumento repressivo (responsabilidade ambiental) sem considerar as razões do juízo formado quando usou o instrumento preventivo (licenciamento). ${ }^{33}$

\footnotetext{
${ }^{31}$ FIGUEIREDO, Guilherme José Purvin. Advocacia Pública e a defesa do meio ambiente à luz do art. 225 da CF. p. 38-39.

32 KRELL, Andreas Joachim. A convivência funcional dos órgãos administrativos e judiciais no controle da discricionariedade no âmbito da proteção ao meio ambiente. p. 26.

33 KRELL, Andreas Joachim. A convivência funcional dos órgãos administrativos e judiciais no controle da discricionariedade no âmbito da proteção ao meio ambiente. p. 32-33
}

Revista de Direito da Cidade, vol. 08, no 3. ISSN 2317-7721 pp.934-951 948 


\section{CONCLUSÃO}

O crescimento disfuncional das grandes (e, mais recentemente, das médias) cidades latinoamericanas aponta para mais uma questão trazida à ordem do dia: a mobilidade urbana. Não se trata de um aspecto restrito ao capitalismo periférico, porém, em áreas já repletas de desafios tradicionalmente enfrentados e não superados, os problemas de mobilidade urbana se apresentam ainda mais inquietantes para o bem-estar da população.

No Brasil, por causa dos grandes eventos (principalmente esportivos) e das reformas urbanas associadas, a mobilidade urbana se tornou um catalisador de demandas sociais. Com efeito, a pauta de reivindicações se mostra bastante difusa e indefinida. Todavia, a falta de mobilidade urbana, ao afetar diretamente o dia-a-dia do cidadão urbano, subtraindo-lhe horas preciosas de descanso e de lazer e intensificando o stress a que é submetido diuturnamente, é uma das faces mais visíveis da questão urbana e assume a linha de frente dos problemas típicos das cidades brasileiras.

Não se nega que a solução dos problemas de mobilidade urbana depende da formulação e implementação de políticas públicas (como investimentos em transporte público, reforma da malha viária e incentivos para modificação de hábitos dos cidadãos) que guiem o desenvolvimento urbano numa direção mais sustentável. Neste sentido, são imprescindíveis não só decisões políticas sérias, mas também uma sustentação técnica para as medidas, com base no planejamento urbano de uma forma geral ou, com escopo mais específico, em planos viários.

Entretanto, ao se reconhecer que a mobilidade urbana é severamente constrangida pelos impactos viários decorrentes da implantação de grandes empreendimentos (a ponto de configurálos como impactos ambientais negativos), confere-se ao licenciamento ambiental o papel de evitar a degradação da qualidade do meio ambiente urbano no que tange também à necessidade de circulação.

A prevenção e a mitigação dos referidos impactos demandam a exposição clara dos efeitos que o empreendimento pode potencial ou efetivamente causar ao tráfego, para que sejam impostas medidas suficientes para sua máxima anulação.

O licenciamento ambiental, então, se apresenta como instrumento jurídico que contribui, para além das políticas públicas de mobilidade urbana, para a tarefa de garantir ao cidadão maior bem-estar na sua relação com o ambiente construído, ao proporcionar o controle dos possíveis impactos viários de empreendimentos urbanos. 


\section{REFERÊNCIAS}

ANTUNES, Paulo de Bessa. Direito Ambiental. 11a ed. Rio de Janeiro: Lumen Juris, 2008.

BAHIA, Luiz Dias; DOMINGUES, Edson Paulo. Estrutura de inovações na indústria automobilística brasileira. Texto para discussão no 1472. Brasília: IPEA, 2010.

BARIFOUSE, Leonardo. Integração e fragmentação no Cadastro Ambiental Rural (CAR). Revista de Direito Ambiental. v. 75, jul./set. 2014, p. 93-111.

O planejamento urbano entre a ordem e o caos. Revista de Direito da Cidade. v. 5, n. 1, 2013, p. 146-169.

BONIZZATO, Luigi. Função ambiental da cidade, Plano Diretor e validade das normas urbanísticas. In: MOTA, Mauricio (coord.). Função social do Direito Ambiental. Rio de Janeiro: Elsevier, 2009.

DALLARI, Adilson Abreu. Instrumentos da política urbana (art. 4ㅇ). In: DALLARI, Adilson Abreu; FERRAZ, Sérgio (org.). Estatuto da Cidade. 2a ed. São Paulo: Malheiros, 2006.

FENSTERSEIFER, Tiago. Direitos fundamentais e proteção do ambiente: a dimensão ecológica da dignidade humana no marco jurídico-constitucional do Estado Socioambiental de Direito. Porto Alegre: Livraria do Advogado, 2008.

FIGUEIREDO, Guilherme José Purvin. Advocacia Pública e a defesa do meio ambiente à luz do art. 225 da CF. In: BENJAMIN, Antonio Herman; FIGUEIREDO, Guilherme José Purvin (coord.). Direito Ambiental e as funções essenciais à justiça. São Paulo: Revista dos Tribunais, 2014.

IPEA. Impactos da redução do imposto sobre produtos industrializados (IPI) de automóveis. Nota técnica no 15, 2009.

KRELL, Andreas Joachim. A convivência funcional dos órgãos administrativos e judiciais no controle da discricionariedade no âmbito da proteção ao meio ambiente: aspectos político-ideológicos da ação civil pública. In: TRENNEPOHL, Curt; TRENNEPOHL, Terence (coord.). Direito Ambiental atual. 1a ed. Rio de Janeiro: Elsevier, 2014.

MACHADO, Paulo Affonso Leme. Direito Ambiental brasileiro. 21a ed. São Paulo: Malheiros, 2013.

MEIRELLES, Hely Lopes. Direito municipal brasileiro. 14a ed. São Paulo: Malheiros, 2006.

MILARÉ, Édis. Direito do ambiente. 8a ed. São Paulo: Revista dos Tribunais, 2013.

MIRRA, Álvaro Luiz Valery. Estudos de impacto de vizinhança no Direito brasileiro. In MARQUES, Claudia Lima; MEDAUAR, Odete; SILVA, Solange Teles da (coord.). O novo Direito Administrativo, Ambiental e Urbanístico: estudos em homenagem a Jacqueline Morand-Deviller. São Paulo: Revista dos Tribunais, 2010. 
PIOVESAN, Flávia. O direito ao meio ambiente e a Constituição de 1988. In: BENJAMIN, Antonio Herman; FIGUEIREDO, Guilherme José Purvin (coord.). Direito Ambiental e as funções essenciais à justiça. São Paulo: Revista dos Tribunais, 2014.

RIBEIRO, Luiz Cesar de Queiroz; RIBEIRO, Marcelo Gomes (org.). IBEU: índice de bem-estar urbano. Rio de Janeiro: Letra Capital, 2013.

SANTOS, Milton. Metrópole corporativa fragmentada: o caso de São Paulo. 2a ed. São Paulo: Edusp, 2009.

SILVA, José Afonso da. Direito Urbanístico brasileiro. 7ạ ed. São Paulo: Malheiros, 2012.

SOARES, Lucéia Martins. Estudo de impacto de vizinhança (arts. 36 a 38). In: DALLARI, Adilson Abreu; FERRAZ, Sérgio (org.). Estatuto da Cidade. 2a ed. São Paulo: Malheiros, 2006.

Trabalho enviado em 13 de junho de 2016.

Aceito em 22 de junho de 2016. 